\title{
STRATEGI EXPERIENTIAL MARKETING DAN LOYALITAS MEREK
}

\author{
Dian Tauriana ${ }^{1}$; Rendy Manlin² \\ 1,2 Jurusan Manajemen, Fakultas Ekonomi dan Bisnis, Universitas Bina Nusantara, \\ Jln. K.H. Syahdan No. 9, Palmerah, Jakarta Barat 11480 \\ dtauriana@binus.edu
}

\begin{abstract}
Consumer experience born from the consumption of a product or service gives a distinct impression in the minds of consumers. This impression creates brand loyalty, provided that the appropriate marketing program is designed to provide a unique experience. Article explores a study that uses primary and secondary data at Bengawan Solo Coffee to see the impact of marketing programs based on experience upon customer loyalty towards the Bengawan Solo Coffee brand. Data were collected by direct interviews of selected respondents through purposive sampling. Furthermore, those data were analyzed using several statistical methods, such as normality tests, the validity and reliability, the classic assumption test, Pearson product moment, and multiple regression. The results shows that there are significant correlation between marketing based on experience (feel, act, and relate) towards brand loyalty. The relationship between experiential marketing (feel and relate) towards brand loyalty is low, while the experiential marketing relationship (act) is quite strong.
\end{abstract}

Keywords: experiential marketing, brand loyalty

\begin{abstract}
ABSTRAK
Pengalaman konsumen yang lahir dari mengkonsumsi sebuah produk atau jasa akan memberikan suatu kesan tersendiri di benak konsumen. Kesan ini akan menciptakan kesetiaan akan merek, asalkan program pemasaran yang dirancang tepat guna dalam menyajikan pengalaman tertentu. Artikel menjelaskan penelitian yang menggunakan data primer dan sekunder pada Bengawan Solo Coffee untuk melihat pengaruh program pemasaran yang berlandaskan pengalaman terhadap kesetiaan konsumen akan merek Bengawan Solo. Data dikumpulkan melalui wawancara personal dari para responden yang terpilih melalui purposive sampling. Selanjutnya, data dianalisis menggunakan beberapa metode statistik, seperti uji normalitas, validitas dan reliabilitas, uji asumsi klasik, pearson product moment, dan regresi berganda. Hasil penelitian menunjukkan bahwa terdapat pengaruh antara pemasaran berlandaskan pengalaman (feel, act, dan relate) terhadap kesetiaan merek. Hubungan antara experiential marketing (feel dan relate) terhadap loyalitas merek adalah rendah, sedangkan hubungan experiential marketing (act) adalah cukup kuat.
\end{abstract}

Kata kunci: experiential marketing, loyalitas merek 


\section{PENDAHULUAN}

Pada masa sekarang, konsumen menganggap fitur, kualitas produk, dan brand image yang positif sebagai sesuatu yang mutlak ada di dalam sebuah produk. Apa yang mereka inginkan sekarang adalah produk, komunikasi, kampanye pemasaran yang menggunakan indera, menyentuh hati, dan menstimulasi pikiran mereka. Konsumen menginginkan produk, komunikasi, kampanye pemasaran yang menawarkan sesuatu yang berbeda dari yang lainnya.

Untuk itu konsep experiential marketing mulai membumi pada dunia pemasaran yang kini telah banyak diterapkan dan mudah ditemui diberbagai jenis perusahaan. Fenomena ini semakin umum terlihat di gerai kopi modern seperti Starbuck's, J.CO, Coffee Bean, dll. agar konsumen tertarik pada produk dan ingin mencoba sekaligus membeli. Akan tetapi, perusahaan tidak berhenti sampai di sini saja, mengingat tujuan dari perusahaan bahwa tidak hanya meyakinkan bahwa produknya layak dibeli. Namun, ada yang lebih penting, yaitu bagaimana perusahaan menciptakan loyalitas konsumen terhadap merek karena konsumen yang loyal akan mendatangkan keuntungan bagi perusahaan dalam jangka waktu yang panjang. Dalam hal ini, peneliti tertarik untuk mempelajari hubungan experiential marketing dalam kaitannya dengan loyalitas merek. Apakah ada hubungan antara masing-masing variabel dari strategi experiential marketing (sense, feel, think, act, relate) terhadap loyalitas merek?. Seberapa kuat hubungan antara variabel dari experiential marketing (sense, feel, think, act, relate) teradap loyalitas merek?. Bagaimana pengaruh dari unsur sense, feel, think, act, relate dalam strategi experiential marketing terhadap loyalitas merek?. Bagaimana tanggapan konsumen terhadap strategi experiential marketing yang diterapkan di Bengawan Solo Coffee?.

Penelitian dilakukan dengan tujuan (1) Mengetahui hubungan antara masing-masing variabel dari experiential marketing (sense, feel, think, act, relate) terhadap loyalitas merek; (2) Mengetahui seberapa kuat hubungan antara variabel dari experiential marketing (sense, feel, think, act, relate) terhadap loyalitas merek; (3) Melihat pengaruh dari unsur sense, feel, think, act, relate dalam strategi experiential marketing terhadap loyalitas merek; (4) Mengetahui tanggapan konsumen terhadap strategi experiential marketing yang diterapkan Bengawan Solo Coffee.

Pengalaman (experience) menurut Bernd H. Schmitt (2008) adalah peristiwa atau kejadian yang memiliki kesan pribadi, yang terjadi sebagai tanggapan atau hasil dari adanya rangsangan atau stimuli (misalnya rangsangan yang disediakan oleh usaha pemasaran, baik sebelum maupun sesudah terjadinya pembelian). Pengalaman (experience) melibatkan seluruh kehidupan dan sering merupakan hasil dari observasi langsung atau partisipasi dalam suatu kejadian, baik secara nyata, berupa mimpi, maupun virtual. Biasanya experience tidak terjadi dengan sendirinya, tetapi harus dipicu. Oleh karena itu, pemasar harus menyediakan atau menciptakan lingkungan dan setting yang tepat untuk menghasilkan custromer experience yang diharapkan. Persepsi seseorang terhadap suatu objek merupakan hasil kerja dari sistem otak, dan tidak sepenuhnya dapat dikontrol, kecuali berupa imajinasi. Ada 5 tipe pengalaman (experience) yang oleh Bernd H. Schmitt disebut Strategic Experiential Modules (SEMs), antara lain (1) Sensory experience atau sense (berdasarkan panca indera); (2) Affective experience atau feel (berdasarkan emosi dan perasaan positif yang timbul); (3) Creatice cognitive experience atau think (berdasarkan daya pikir); (4) Physical experience atau act (berdasarkan tindakan fisik dan interaksi); (5) Social identity experience atau relate (berdasarkan upaya menghubungkan merek dengan diri konsumen, orang lain, atau keterkaitan dengan budaya).

Elena Delgado-Ballester mengungkapkan loyalitas merek sebagai ukuran seberapa besar konsumen loyal terhadap suatu merek. Ukuran ini menggambarkan tentang mungkin tidaknya seorang pelanggan beralih ke merek produk lain, terutama jika pada merek tersebut didapati adanya perubahan baik menyangkut harga ataupun atribut lain. Loyalitas merek merupakan inti dari brand equity yang menjadi gagasan sentral dalam pemasaran. Apabila loyalitas merek meningkat, maka kerentanan kelompok pelanggan dari serangan pesaing dapat dikurangi karena loyalitas merek secara langsung 
dapat diartikan sebagai penjualan di masa depan. Loyalitas merek diukur dengan pembelian rutin, tingkat pembelian ulan, persentase pembelian, dan jumlah merek yang dibeli.

Penelitian ini hendak menguji beberapa hipotesis seperti berikut ini.

$\mathrm{H}_{1}=$ terdapat hubungan antara strategi experiential marketing (sense) terhadap loyalitas merek

$\mathrm{H}_{1} \quad=$ terdapat hubungan antara strategi experiential marketing (feel) terhadap loyalitas merek

$\mathrm{H}_{1}=$ terdapat hubungan antara strategi experiential marketing (think) terhadap loyalitas merek

$\mathrm{H}_{1}=$ terdapat hubungan antara strategi experiential marketing (act) terhadap loyalitas merek

$\mathrm{H}_{1}=$ terdapat hubungan antara strategi experiential marketing (relate) terhadap loyalitas merek

$\mathrm{H}_{1}=$ terdapat pengaruh antara strategi experiential marketing (sense, feel, think, act, relate) terhadap loyalitas merek.

Untuk melakukan penelitian secara akurat, peneliti merancang suatu desain (Tabel 1).

Tabel 1 Desain Studi

\begin{tabular}{|c|c|c|c|c|}
\hline \multirow{2}{*}{$\begin{array}{c}\text { Tujuan } \\
\text { Penelitian }\end{array}$} & \multicolumn{3}{|c|}{ Desain Penelitian } & \multirow[b]{2}{*}{ Time Horizon } \\
\hline & $\begin{array}{c}\text { Jenis } \\
\text { Penelitian }\end{array}$ & $\begin{array}{c}\text { Metode yang } \\
\text { digunakan }\end{array}$ & Unit Analisis & \\
\hline $\mathrm{T}-1$ & Asosiatif & Descriptive Survey & Individu->konsumen & Cross Section \\
\hline $\mathrm{T}-2$ & Asosiatif & Descriptive Survey & Individu->konsumen & Cross Section \\
\hline $\mathrm{T}-3$ & Kausal & Descriptive Survey & Individu->konsumen & Cross Section \\
\hline $\mathrm{T}-4$ & Deskriptif & Descriptive Survey & Individu $\rightarrow$ konsumen & Cross Section \\
\hline
\end{tabular}

Sumber: Hasil pengolahan Penulis (2008)

Tabel 2 Operasionalisasi Variabel Penelitian

\begin{tabular}{|c|c|c|c|c|c|}
\hline Variabel & Konsep Variabel & $\begin{array}{c}\text { Sub } \\
\text { Variabel }\end{array}$ & Indikator & Ukuran & Skala \\
\hline $\begin{array}{l}\text { Experiential } \\
\text { Marketing }\end{array}$ & $\begin{array}{l}\text { konsep pemasaran dari } \\
\text { suatu produk atau jasa } \\
\text { yang menciptakan } \\
\text { pengalaman bagi } \\
\text { konsumen (customer } \\
\text { experience) melalui kelima } \\
\text { strategic experiential } \\
\text { modules (SEMs) yaitu } \\
\text { pengalaman berdasarkan } \\
\text { panca indera (sense), } \\
\text { perasaan dan emosi (feel), } \\
\text { pikiran (think), tindakan, } \\
\text { perilaku, dan gaya hidup } \\
\text { (act) serta upaya konsumen } \\
\text { dalam menghubungkan } \\
\text { merek dengan dirinya, } \\
\text { orang lain, atau budaya } \\
\text { (relate) }\end{array}$ & $\begin{array}{l}\text { 4. Act } \\
\text { 5. Relate }\end{array}$ & $\begin{array}{ll}\text { - } & \text { Logo yang menarik } \\
\text { - } & \text { Desain interior yang menarik } \\
\text { - } & \text { Aroma yang nikmat } \\
\text { - } & \text { Rasa kopi yang nikmat } \\
\text { - } & \text { Perasaan senang saat } \\
& \text { mengkonsumsi kopi } \\
\text { - } & \text { Perasaan bangga ketika minum kopi } \\
& \text { di gerai kopi } \\
\text { - } & \text { Pelayanan yang diberikan membuat } \\
& \text { puas } \\
\text { - } & \text { Perasaan senang dengan keramahan } \\
& \text { yang diberikan oleh barista } \\
& \text { Perasaan nyaman saat berada di } \\
& \text { gerai kopi } \\
\text { - } & \text { Mendorong untuk mengenal } \\
& \text { beragam jenis kopi } \\
\text { - } & \text { Nama-nama kopi yang unik } \\
\text { - } & \text { Pilihan rasa yang beragam } \\
\text { - } & \text { Harga kopi sesuai dengan kualitas } \\
\text { - } & \text { Suka mengkonsumsi kopi } \\
\text { - } & \text { Menjadi lebih perduli dengan } \\
& \text { kualitas kopi. } \\
\text { - } & \text { Bagian dari gaya hidup } \\
\text { - } & \text { Promosi } \\
\text { - } & \text { Merasa menjadi bagian kaum } \\
& \text { metropolis } \\
\text { - } & \text { Mencerminkan pergaulan kelas atas } \\
\text { - } & \text { Mencerminkan gaya hidup modern } \\
\end{array}$ & Interval & Likert \\
\hline
\end{tabular}


Tabel 2 Operasionalisasi Variabel Penelitian (continued)

\begin{tabular}{|c|c|c|c|c|c|}
\hline \multirow[t]{3}{*}{$\begin{array}{l}\text { Brand } \\
\text { Loyalty }\end{array}$} & $\begin{array}{l}\text { Loyalitas merek merupakan inti } \\
\text { dari brand equity yang menjadi } \\
\text { gagasan sentral dalam } \\
\text { pemasaran. Apabila loyalitas } \\
\text { merek meningkat, maka } \\
\text { kerentanan kelompok pelanggan } \\
\text { dari serangan pesaing dapat } \\
\text { dikurangi. Karena loyalitas } \\
\text { merek secara langsung dapat } \\
\text { diartikan sebagai penjualan di } \\
\text { masa depan. }\end{array}$ & $\begin{array}{l}\text { Commited } \\
\text { Buyer } \\
\text { Likes The } \\
\text { Brand } \\
\text { Satisfied } \\
\text { Buyer }\end{array}$ & $\begin{array}{l}\text { Merekomendasikan kepada orang lain } \\
\text { Membeli produk kembali } \\
\text { Lebih menyukai membeli kopi di } \\
\text { gerai disukai daripada digerai lainnya } \\
\text { Membeli produk kembali } \\
\text { Kualitas kopi membuat saya puas }\end{array}$ & Interval & \\
\hline & & $\begin{array}{l}\text { Habitual } \\
\text { Buyer }\end{array}$ & Membeli produk kembali & \multirow{2}{*}{\multicolumn{2}{|c|}{ Likert }} \\
\hline & & Switcher & $\begin{array}{l}\text { Tetap membeli kopi jika harga kopi } \\
\text { dinaikkan }\end{array}$ & & \\
\hline
\end{tabular}

Sumber: Hasil pengolahan Penulis, 2008

Data yang terkumpul diperoleh dari para pengunjung objek studi/penelitian, yaitu Bengawan Solo Coffee Mall Taman Anggrek, Mal Ciputra, Mal Kelapa Gading, dan Summarecon Mall Serpong, yang dipilih menggunakan metode purposive sampling.

Tabel 3 Jenis dan Sumber Data

\begin{tabular}{ccc}
\hline Tujuan & Sumber Data & Jenis Data \\
\hline $\mathrm{T}-1$ & Primer - Kuesioner & Kualitatif \\
$\mathrm{T}-2$ & Primer - Kuesioner & Kualitatif \\
$\mathrm{T}-3$ & Primer - Kuesioner & Kualitatif \\
$\mathrm{T}-4$ & Primer - Kuesioner & Kualitatif \\
& & \\
\hline
\end{tabular}

Sumber: Hasil pengolahan Penulis, 2008

Keterangan :

$\mathrm{T}-1$ : Untuk mengetahui hubungan antara masing-masing variabel dari experiential marketing (sense, feel, think, act, relate) terhadap loyalitas merek.

T-2 : Untuk mengetahui seberapa kuat hubungan antara variabel dari experiential marketing (sense, feel, think, act, relate) terhadap loyalitas merek.

T-3 : Untuk mengetahui pengaruh dari unsur sense, feel, think, act, relate dalam strategi experiential marketing terhadap loyalitas merek.

T-4 : Untuk mengetahui tanggapan konsumen terhadap strategi experiential marketing yang diterapkan Bengawan Solo Coffee.

Metode menganalisis data yang digunakan adalah uji normalitas, reliabilitas, validitas, dan uji penyimpangan asumsi klasik. Setelah itu, data dianalisis lebih lanjut menggunakan analisis korelasi Pearson Product Moment, dengan rumusan untuk r sebagai berikut. 


$$
r_{x y}=\frac{n\left(\sum X Y\right)-\left(\sum X\right) \cdot\left(\sum Y\right)}{\sqrt{\left\{n \cdot \sum X^{2}-\left(\sum X\right)^{2}\right\}:\left\{n \cdot \sum Y^{2}-\left(\sum Y\right)^{2}\right\}}}
$$

Korelasi PPM dilambangkan (r) dengan ketentuan nilai $\mathrm{r}$ tidak lebih dari harga $(-1 \leq \mathrm{r} \leq+1)$. Apabila nilai $r=-1$, artinya korelasinya negatif sempurna; $r=0$, artinya tidak ada korelasi; dan $r=1$, berarti korelasinya sangat kuat. Untuk pengujian kelayakan model sebagai dasar pembuatan keputusan disebut uji F. Hipotesis yang akan diuji adalah sebagai berikut.

$\mathrm{H}_{0}: \mathrm{b}_{1}=\mathrm{b}_{2}=0$ ( tidak terdapat pengaruh dari $\mathrm{X}_{1}$ dan $\mathrm{X}_{2}$ terhadap $\mathrm{Y}$ )

$\mathrm{H}_{1}: \mathrm{b}_{1}=\mathrm{b}_{2} \neq 0\left(\right.$ terdapat pengaruh dari $\mathrm{X}_{1}$ dan $\mathrm{X}_{2}$ terhadap $\left.\mathrm{Y}\right)$

Rumus dari uji F (Rangkuti, 2002, p154) :

$\mathbf{F}_{0}=$

$$
\frac{R^{2} / k}{\left(1-R^{2}\right)(N-k-1)}
$$

Dengan menggunakan $\mathrm{df}=\mathrm{n}-\mathrm{k}-1$

Df $=$ derajat kebebasan

$\mathrm{k}=$ jumlah variabel independen

$\mathrm{n} \quad=$ banyaknya sampel

Jika $\mathrm{F}_{0}>\mathrm{F}_{\text {tabel, }}$, maka $\mathrm{H}_{0}$ ditolak, sebaliknya kalau $\mathrm{F}_{0}<\mathrm{F}_{\text {tabel, }}$ maka $\mathrm{H}_{\mathrm{o}}$ diterima. Dengan tingkat kepercayaan $95 \%$.

\section{PEMBAHASAN}

\section{Hasil Penelitian}

Dari hasil pengujian normalitas diperoleh hasil sebagai berikut (Tabel 4). Berdasarkan tabel hasil uji normalitas (Tabel 4), dapat diketahui bahwa nilai signifikansi untuk variabel sense sebesar 0,072 ; untuk variabel feel sebesar 0,178; untuk variabel think sebesar 0,052; untuk variabel act sebesar 0,063 ; untuk variabel relate sebesar 0,066 ; dan untuk variabel loyalitas merek sebesar 0,059 . Karena signifikansi untuk seluruh variable lebih besar dari 0,05 , maka dapat disimpulkan bahwa data pada variabel sense, feel, think, act, dan loyalitas merek berdistribusi normal. Angka statistik menunjukan semakin kecil nilainya maka distribusi data semakin normal.

Tabel 4 Uji Normalitas dengan Kolmogorov-Smirnov

\begin{tabular}{cccc}
\hline Variabel & Statistic & Df & Sig. \\
\hline Sense & 0,085 & 100 & 0,072 \\
Feel & 0,075 & 100 & 0,178 \\
Think & 0,088 & 100 & 0,052 \\
Act & 0,086 & 100 & 0,063 \\
Relate & 0,086 & 100 & 0,066 \\
Loyalitas Merek & 0,087 & 100 & 0,059 \\
\hline
\end{tabular}

Sumber: Data diolah dengan SPSS 15 
Pengujian asumsi klasik menunjukkan hasil sebagai berikut (Tabel 5). Berdasarkan tabel hasil uji heteroskedastisitas (Tabel 5), dapat dilihat bahwa nilai $\mathrm{T}$ Hitung dari kelima variabel, di mana LnX1, yaitu sense adalah sebesar 0,400; LnX2, yaitu feel adalah sebesar -1,399; LnX3, yaitu think adalah sebesar -0,714; LnX4, yaitu act adalah sebesar -0,687; dan LnX5, yaitu relate adalah sebesar 0,232 . Sedangkan nilai $\mathrm{T}$ Tabel dengan total $\mathrm{df}=\mathrm{n}-2$ atau $100-2=98$ pada pengujian 2 sisi (signifikansi 0,025), didapat nilai $\mathrm{T}$ Tabel sebesar 1.972. Karena nilai t hitung (sense adalah 0,400; feel adalah sebesar -1,399; think adalah sebesar -0,714; act adalah sebesar -0,687; dan relate adalah sebesar 0,232 ) berada pada $-\mathrm{T}$ Tabel $<\mathrm{T}$ Hitung $<\mathrm{T}$ Tabel. Dengan ini, dapat disimpulkan bahwa tidak ditemukannya masalah heteroskedastisitas.

Tabel 5 Uji Heterokedastisitas

\begin{tabular}{cc}
\hline Model & T \\
\hline LnX1 & 0,400 \\
LnX2 & $-1,399$ \\
LnX3 & $-0,714$ \\
LnX4 & $-0,687$ \\
LnX5 & $-0,232$ \\
\hline
\end{tabular}

Sumber: Data diolah dengan SPSS 15

Berdasarkan hasil uji korelasi, maka didapatkan nilai hubungan dari masing-masing variabel experiential marketing terhadap loyalitas merek sebagai berikut (Tabel 6).

Tabel 6 Uji Korelasi Dengan Pearson's Product Moment

\begin{tabular}{cc}
\hline Subvariabel & Hasil $r$ \\
\hline Sense & 0,119 \\
Feel & 0,387 \\
Think & 0,122 \\
Act & 0,443 \\
Relate & 0,203 \\
\hline
\end{tabular}

Sumber: Data diolah dengan SPSS 15

Berdasarkan pada tabel $r$ dengan $\mathrm{N}=100$ dan tingkat signifikan 0.05 adalah 0.195 , maka hasil yang didapat adalah sebagai berikut. Pertama, Sense (X1). $\mathrm{H}_{0}: \mu=$ tidak terdapat hubungan antara strategi experiential marketing (sense) dan loyalitas merek Bengawan Solo Coffee. $\mathrm{H}_{1}: \mu \neq$ terdapat hubungan antara strategi experiential marketing (sense) dan loyalitas merek Bengawan Solo Coffee. Berdasarkan Tabel 6, peneliti menyimpulkan bahwa tidak adanya hubungan antara strategi experiential marketing (sense) dan loyalitas merek Bengawan Solo Coffee karena hasil $\mathrm{r}$ adalah 0.119 dan lebih rendah dari tabel r, yaitu sebesar 0,195.

Kedua, Feel (X2). $\mathrm{H}_{0}: \mu=$ tidak terdapat hubungan antara strategi experiential marketing (feel) terhadap loyalitas merek Bengawan Solo Coffee. $\mathrm{H}_{1}: \mu \neq$ terdapat hubungan antara experiential marketing (feel) dan loyalitas merek Bengawan Solo Coffee. Berdasarkan Tabel 6, peneliti menyimpulkan adanya hubungan antara strategi experiential marketing (feel) dan loyalitas merek Bengawan Solo Coffee karena hasil r adalah 0.387 dan lebih tinggi dari tabel r, yaitu sebesar 0,195. 
Ketiga, Think (X3). $\mathrm{H}_{0}: \mu=$ tidak terdapat hubungan antara strategi experiential marketing (think) terhadap loyalitas merek Bengawan Solo Coffee. $\mathrm{H}_{1}: \mu \neq$ terdapat hubungan antara experiential marketing (think) dan loyalitas merek Bengawan Solo Coffee. Berdasarkan Tabel 6, peneliti menyimpulkan tidak adanya hubungan antara strategi experiential marketing (think) dan loyalitas merek Bengawan Solo Coffee karena hasil $r$ adalah 0,122 dan lebih rendah dari tabel $r$, yaitu sebesar 0,195 .

Keempat, Act (X4). $\mathrm{H}_{0}: \mu=$ tidak terdapat hubungan antara strategi experiential marketing (act) terhadap loyalitas merek Bengawan Solo Coffee. $\mathrm{H}_{1}: \mu \neq$ terdapat hubungan antara experiential marketing (act) dan loyalitas merek Bengawan Solo Coffee. Berdasarkan Tabel 6, peneliti menyimpulkan adanya hubungan antara strategi experiential marketing (act) dan loyalitas merek Bengawan Solo Coffee karena hasil $r$ adalah 0,443 dan lebih tinggi dari tabel r, yaitu sebesar 0,195.

Kelima, Relate (X5). $\mathrm{H}_{0}: \mu=$ tidak terdapat hubungan antara strategi experiential marketing (relate) terhadap loyalitas merek Bengawan Solo Coffee. $\mathrm{H}_{1}: \mu \neq$ terdapat hubungan antara experiential marketing (relate) dan loyalitas merek Bengawan Solo Coffee. Berdasarkan Tabel 6, peneliti menyimpulkan adanya hubungan antara strategi experiential marketing (relate) dan loyalitas merek Bengawan Solo Coffee karena hasil $r$ adalah 0,203 dan lebih tinggi dari tabel $r$, yaitu sebesar 0,195

\section{Analisis Regresi Berganda}

Hasil perhitungan dari regresi berganda ditunjukkan pada Tabel 7. Berdasarkan tabel hasil uji regresi berganda mengenai pengaruh strategi experiential marketing (sense, feel, think, act, relate) terhadap loyalitas merek pada diatas, maka dapat disimpulkan sebagai berikut. Pertama, Standart error of the Estimate (SEE) adalah sebesar 0,46747. Makin kecil SEE akan membuat model regresi semakin tepat dalam memprediksi variabel independent. Kedua, dari nilai $\mathrm{R}$ di atas dapat diketahui bahwa $\mathrm{R}=0,536$; menunjukan bahwa terdapat hubungan yang cukup kuat atau positif antara strategi experiential marketing (sense, feel, think, act, relate) terhadap loyalitas merek. Hubungan yang cukup kuat berarti strategi experiential marketing (sense, feel, think, act, relate) mempengaruhi loyalitas merek, sedangkan hubungan yang positif berarti setiap peningkatan strategi experiential marketing mempengaruhi tingkat loyalitas pelanggan. Ketiga, sedangkan R square $=0,287 \times 100 \%=28,7 \%$. Yang artinya adalah $\mathrm{R}$ square menunjukkan bahwa pengaruh strategi experiential marketing (sense, feel, think, act, relate) terhadap loyalitas merek sebesar 28,7\% (angka $\mathrm{R}$ square adalah 0,287). Selebihnya sebesar $71,3 \%(100 \%$ - 28,7\%) dipengaruhi oleh faktor-faktor lain.

Tabel 7 Uji Regresi Berganda

\begin{tabular}{ccccc}
\hline Model & R & R Square & $\begin{array}{c}\text { Adjusted } \\
\text { R Square }\end{array}$ & $\begin{array}{c}\text { Std. Error } \\
\text { of the Estimate }\end{array}$ \\
\hline 1 & 0,536 & 0,287 & 0,249 & 0,46747 \\
\hline
\end{tabular}

Sumber: Data diolah dengan SPSS 15

Penelitian ini membahas tentang pengaruh strategi experiential marketing terhadap loyalitas merek. Experiential marketing itu sendiri terbagi dalam 5 subvariable, yaitu sense, feel, think, act, dan relate. Dari uraian hasil penelitian di atas, maka dapat diperoleh hasil penelitian sebagai berikut. 
Pertama, untuk nilai sense dapat diketahui bahwa nilai $\mathrm{r}$ hitung lebih rendah $(<)$ dari $\mathrm{r}$ tabel, yaitu sebesar $0,119<0,195$. Peneliti menyimpulkan bahwa tidak adanya hubungan antara strategi experiential marketing (sense) terhadap loyalitas merek Bengawan Solo Coffee. Kedua, untuk nilai feel dapat diketahui bahwa nilai $\mathrm{r}$ hitung lebih beasr $(>)$ dari $\mathrm{r}$ tabel, yaitu 0,387 $>0,195$. Peneliti menyimpulkan bahwa adanya hubungan antara strategi experiential marketing (feel) terhadap loyalitas merek Bengawan Solo Coffee. Ketiga, untuk nilai think dapat diketahui bahwa nilai $\mathrm{r}$ hitung lebih rendah $(<)$ dari $r$ tabel, yaitu sebesar $0,122<0,195$. Peneliti menyimpulkan bahwa tidak adanya hubungan antara strategi experiential marketing (think) terhadap loyalitas merek Bengawan Solo Coffee. Keempat, untuk nilai act dapat diketahui bahwa nilai $\mathrm{r}$ hitung lebih beasr $(>)$ dari $\mathrm{r}$ tabel, yaitu $0,443>0,195$. Peneliti menyimpulkan bahwa adanya hubungan antara strategi experiential marketing (act) terhadap loyalitas merek Bengawan Solo Coffee.

Kelima, untuk nilai relate dapat diketahui bahwa nilai $\mathrm{r}$ hitung lebih besar $(>)$ dari $\mathrm{r}$ tabel, yaitu $0,203>0,195$. Peneliti menyimpulkan bahwa adanya hubungan antara strategi experiential marketing (relate) terhadap loyalitas merek Bengawan Solo Coffee. Keenam, dapat dilihat nilai $r$ hitung untuk feel adalah 0,387. Berdasarkan interpretasi koefisien korelasi nilai $\mathrm{r}$ pada Tabel 7, peneliti menyimpulkan bahwa hubungan antara experiential marketing (feel) terhadap loyalitas merek adalah rendah. Ketujuh, dapat dilihat nilai $\mathrm{r}$ hitung untuk act adalah 0,443. Berdasarkan interpretasi koefisien korelasi nilai $\mathrm{r}$ pada Tabel 7, peneliti menyimpulkan bahwa hubungan antara experiential marketing (act) terhadap loyalitas merek adalah cukup kuat.

Kedelapan, dapat dilihat nilai $\mathrm{r}$ hitung untuk relate adalah 0,203 . Berdasarkan interpretasi koefisien korelasi nilai $\mathrm{r}$ pada Tabel 7, peneliti menyimpulkan bahwa hubungan antara experiential marketing (relate) terhadap loyalitas merek adalah rendah. Kesembilan, besarnya pengaruh X1, X2, X3, X4, X5 terhadap Y dapat diketahui dari angka R Square, yaitu 0,287. Hal ini berarti bahwa 28,7\% loyalitas merek Bengawan Solo Coffee dipengaruhi oleh strategi experiential marketing (sense, feel, think, act, relate), sedangkan sisanya $(100 \%-25,4 \%=71,3 \%)$ dipengaruhi oleh faktor-faktor lain. Kesepuluh, merubah identitas sosial mereka jika mengkonsumsi merek produk tertentu tergolong sedang, artinya konsumen mungkin merasakan pengalaman yang terbentuk melalui relate ini. Hal ini menandakan bahwa Bengawan Solo Coffee belum sepenuhnya berhasil menciptakan pengalaman yang menggugah relate konsumen. Kesebelas, berdasarkan nilai yang didapat dari pernyataan-pernyataan dalam unsur loyalitas merek, diperoleh nilai mean sebesar 3,75, yang berarti loyalitas merek konsumen terhadap Bengawan Solo Coffee tergolong dalam loyalitas tinggi.

\section{PENUTUP}

Berdasarkan hasil penelitian maka dapat disimpulkan sebagai berikut. Pertama, dari kelima subvariabel yang ada dalam experiential marketing, 3 di antaranya, yaitu feel, act, dan relate memiliki hubungan tehadap loyalitas merek, sedangkan 2 subvariabel lain, yaitu sense dan think tidak memiliki hubungan terhadap loyalitas merek. Kedua, hubungan antara experiential marketing (feel dan relate) terhadap loyalitas merek adalah rendah, sedangkan hubungan experiential marketing (act) adalah cukup kuat. Ketiga, terdapat pengaruh strategi experiential marketing (sense, feel, think, act, relate) terhadap loyalitas merek. Keempat, pengalaman yang didapat konsumen melalui strategi experiential marketing (sense, feel, think, act) adalah tinggi, sedangkan pengalaman yang didapat melalui relate tergolong sedang dan loyalitas merek konsumen terhadap Bengawan Solo Coffee tergolong dalam loyalitas tinggi.

Peneliti menyarankan kepada pihak manajemen untuk (1) mengidentifikasi lebih cermat tindakan atau stimulus pemasaran yang benar-benar dapat menciptakan unsur sense, feel, think, act, dan relate dalam strategi experiential marketing di benak konsumen; (2) memberikan perhatian yang 
lebih terhadap unsur sense dan think dalam strategi experiential marketing karena kedua unsur tersebut belum memberikan dampak yang positif (tidak ada hubungan) terhadap loyalitas merek, sehingga kedua variabel atau atribut tersebut dapat meberikan kontribusi yang signifikan terhadap loyalitas merek; dan (3) penelitian selanjutnya diharapkan dapat memberikan masukan dari penggunaan strategi experiential marketing terhadap loyalitas merek.

\section{DAFTAR PUSTAKA}

Ajzen, I., and Fishbein, M. (1980). Understanding attitudes and predicting social behavior, Englewood Cliffs, NJ: Prentice Hall.

Baldinger, A.L., and Rubinson, J. (1996). Brand loyalty: The link between attitude and behavior. Journal of Advertising Research, 36, 22-34.

Day, G.S. (1969). A two-dimensional concept of brand loyalty. Journal of Advertising Research, 9, 29-35

Delgado-Ballester, E., and Munumeura, J.L. (2005). Does brand trust matter to brand equity?. Journal of Product and Brand Management, 14.

Jacoby, J. (1971). A model of multi-brand loyalty. Journal of Advertising Research, 11, 25-31.

Jacoby, J., and Chestnut, R. (1978). Brand loyalty: Measurement and management, New York, YN: John Wiley \& Sons.

Mitchell, M., and Mitchell, S. (2000). Consumer experience tourism: A powerful toof for food and beverage producers. Journal of Food Products Marketing, 6(3), 1-16.

Schimdt, B.H. (2008). Experiential marketing, New York, YN: Word-Press. 